\title{
Co-ordination betweeen Elongation and Division in Escherichia coli Mediated by the wee Gene Product
}

\author{
By ADELA G. DE LA CAMPA, ENCARNACIÓN MARTÍNEZ-SALAS, \\ ANTONIO TORMO AND MIGUEL VICENTE* \\ Instituto de Biologia Celular, Consejo Superior de Investigaciones Cientificas, Velázquez 144. \\ 28006-Madrid, Spain
}

(Received 26 October 1983; revised 13 April 1984)

\begin{abstract}
A procedure to construct strains of Escherichia coli containing conditional lethal mutations in two different genes was used to construct a ftsA-3(ts) wee(Am) supF(ts) strain. This strain, OV25-7, was used to ascertain whether the wee gene product (Wee) acts at the level of regulation of cell elongation or at the co-ordination of elongation and division. The mass per unit length and the buoyant density of cells in the absence of Wee increased only if division was allowed, as in the case of strain OV-25 (wee(Am) supF (ts)), but not when it was inhibited, as in strain OV-25-7. These results suggested that in $E$. coli the wee gene product was acting at the level of coordination between elongation and cell division.
\end{abstract}

\section{INTRODUCTION}

Co-ordination of cell growth, elongation and division during balanced growth of Escherichia coli produces cells in which length and age are tightly correlated (Cullum \& Vicente, 1978). Cell growth regulates chromosomal replication by means of a mass control on the initiation of replication (Donachie, 1968). From then on, replication, elongation and division follow pathways that are largely independent of each other (Donachie et al., 1976). That the pathways for replication and division are co-ordinated at a later stage of the bacterial life cycle is suggested by the requirement of protein synthesis upon completion of DNA replication for division to occur (Jones \& Donachie, 1973; Tormo et al., 1980). It is not known whether division and elongation are actively co-ordinated as well, or, conversely, if the observed correlation between length and age is the passive result of the control and co-ordination exerted on the cell by the initiation mass and termination proteins (Jones \& Donachie, 1973).

A strain of $E$. coli OV-25, harbouring an amber allele of wee in a temperature sensitive suppressor (tyrTA81) background has been found still to be able to elongate, although accumulation of length occurred at a rate slightly lower than in the wild-type (Martinez-Salas \& Vicente, 1980). In the absence of the wee gene product (Wee), independently of the growth rate the cells became short and their length diminished to mean values that were very close to those predicted for cells growing with infinite generation time (Donachie et al., 1976). As the absence of Wee did not interfere with the accumulation of mass, the cells became denser than the parental strain and finally died (Martinez-Salas \& Vicente, 1980). From these results it has been proposed that Wee plays a regulatory role in elongation, either by controlling its rate according to the growth rate, or by co-ordinating the elongation and division pathways (Martinez-Salas \& Vicente, 1980).

We here report experiments designed to enable the action of the wee gene product to be ascribed either to the control of elongation or to the co-ordination between elongation and division. 


\section{METHODS}

Bacterial strains and grow'th conditions. Escherichia coli strain W-3110 (wild-type) was used to propagate phage lysates. OV-25 is a derivative of $\mathrm{K} 12$ strain $\mathrm{OV}-2$ : $\mathrm{F}^{-}$ilv his leu thy A(deo) ara(Am) lac $125($ Am) galU $42 \mathrm{galE}$ $\operatorname{trp}(\mathrm{Am}) \operatorname{tsx}(\mathrm{Am}) \operatorname{tr} T$ (supF A81(ts)) (Donachie et al., 1976) containing a wee(Am) mutation and auxotrophic marker (met(ts) arg(ts)) (Martinez-Salas \& Vicente, 1980). Strain D-3 is a leu ${ }^{+} f(t s A-3(t s)$ derivative of OV-2 (Tormo et al, 1980). OV-25-7 is a double mutant wee(Am) fisA-3(ts) strain in an OV-25 background (see Results).

Nutrient broth was used to grow all the strains. Conditions to attain balanced growth of the bacterial populations have been published previously (Martinez-Salas \& Vicente, 1980).

Cell parameter measurements. Cell numbers were measured by using a Petroff-Hauser counting chamber, and particle numbers were measured in a Coulter-counter, as described previously (Martinez-Salas \& Vicente, 1980). Buoyant density measurements were performed by sedimentation to equilibrium in $16 \%$ Ludox $/ 3.75 \%$ polyvinylpyrrolidone self-forming gradients, as described previously (Martinez-Salas et al., 1981). Protein concentration was measured colorimetrically as described previously (Martinez-Salas et al., 1981). Photomicrography of cells layered on top of agar/azide coated slides was done as described by Donachie et al. (1976). Cell length was measured from enlarged photomicrographs with the aid of a Hewlett-Packard $9111 \mathrm{~A}$ graphics tablet coupled to a HP-85 computer. The basic section of the software was based on the $9111 \mathrm{~A} / \mathrm{HP}-85$ system tutorial that includes a continuous digitizing mode, needed in order to measure the meandering filaments present in some of the samples. A listing of the BASIC-written program (MLENG) is available on request. Histograms were drawn from the data using the program HISTO of the Hewlett-Packard HP-85 standard pack.

Inhibition of cell division by Furazlocillin. Furazlocillin to a final concentration of $2 \mu \mathrm{g} \mathrm{ml} \mathrm{I}^{-1}$ was used to inhibit cell division. This antibiotic (BAY k 4999) was a gift of Bayer (Wuppertal, FRG).

Genetic procedures. PI-mediated transduction was performed as previously described (Martinez-Salas \& Vicente, 1980). Lysogenization, with $\lambda 634$ (imm21) [supF] (Borck et al., 1976) and $\lambda 16-2\left(\mathrm{imm} 21 \times\left(\mathrm{fts} A^{+}\right]\right.$ (Lutkenhaus \& Donachie, 1979), and displacement of the prophage by $\lambda b 2$ red (Herskowitz \& Hagen, 1980) were done by spot tests on BBL trypticase agar (Arber et al., 1983).

\section{RESULTS}

\section{Construction of a double mutant fts A wee}

We reasoned that blocking cell division in the absence of Wee might have two different results, depending upon its role. If Wee regulates elongation rate, a division block in a wee(Am) strain should produce filaments of a shorter length, equal mass and higher buoyant density than those produced by a similar inhibition in a wee ${ }^{+}$strain. On the other hand, if the action of Wee takes place at the (up to now hypothetical) co-ordination between elongation and division, the buoyant density of the filaments, formed after blocking division in the absence of Wee, should be normal.

Genetic, rather than chemical, inhibition of cell division was preferred for our purpose, in order to avoid metabolic side-effects or gross changes in the macromolecular composition of the cell. The $f t s A-3(t s)$ allele blocks division at the restrictive temperature from the end of replication until the completion of the septum (Tormo et al., 1980). We then constructed a strain carrying both wee(Am) and fts $A-3$ mutations in a sup $F(t s) t r p(A m)$ background. The main difficulty in the construction and analysis of such a strain is that both the ftsA-3 mutation and the combination of wee $(\mathrm{Am})$ plus $\sup F(\mathrm{ts})$ mutations result in a temperature sensitive phenotype. This problem was obviated during the construction (see Fig. 1) by first lysogenizing strain OV-25 wee(Am) supF(ts) leu with a $\lambda 634[$ supF] (Borck et al., 1976), thus producing a temperature insensitive phenotype due to the dominance of $\sup F$ over the ts allele. The fts $A-3$ allele was then introduced with $\mathrm{Pl}$ into the lysogen, by co-transduction with $\mathrm{leu}^{+}$and selection of temperature sensitive clones. A strain in which expression of the wee(Am) phenotype is possible at $42{ }^{\circ} \mathrm{C}$ was then obtained by displacement of the $\lambda 634(\mathrm{imm} 2 \mathrm{l})[\sup F]$ prophage mediated by the int function of a heteroimmune $\lambda b 2$ red (Herskowitz \& Hagen, 1980). That the resultant strain, OV-25-7, was in fact a double ftsA-3(ts) wee(Am) mutant, instead of a single one, was proved by demonstrating in it the independent presence both of an $f t s A$ mutation and of another mutation suppressible by supF, as follows (see Fig. 2). Lysogenization of OV-25-7 with $\lambda 16-$ $2\left[f t s A^{+}\right]$(Lutkenhaus \& Donachie, 1979) gave rise to temperature sensitive lysogens, suggesting either that the prophage had lost its $f t s A^{+}$or that some essential function, other than $f t s A$, was impaired in OV-25-7. Simultaneous reversion of the lysogen, to both temperature resistance and 


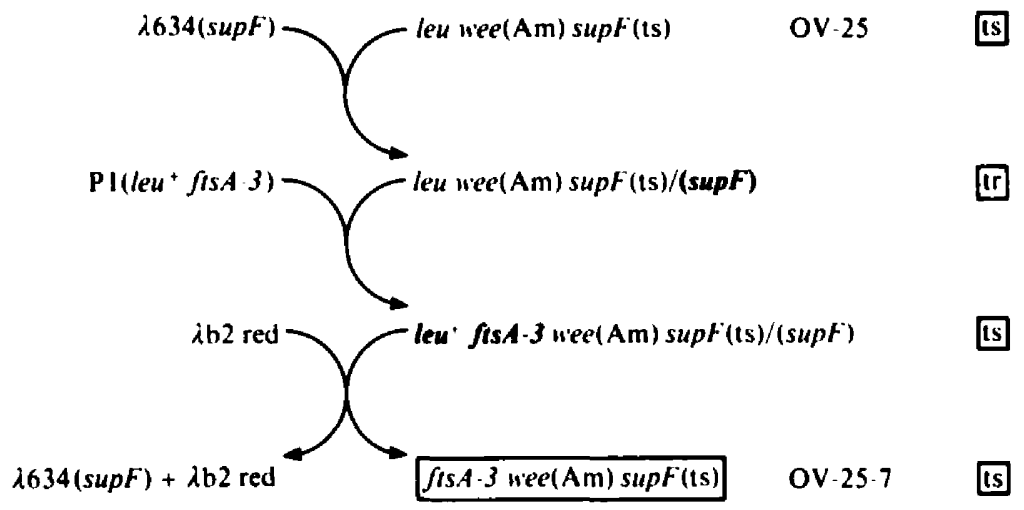

Fig. 1. Construction of a strain containing mutations in the $f(s, A$ and wee genes. The relevant genotypes of the bacterial and bacteriophage strains used in the steps of the procedure described in the text are indicated. The resultant phenotype of the bacterial strains, either ts or $t$, is indicated. Strain name has been assigned only to the resultant $f t s A \cdot 3(\mathrm{ts})$ wee(Am) supF(ts) strain. Markers relevant for one particular step are in bold type.

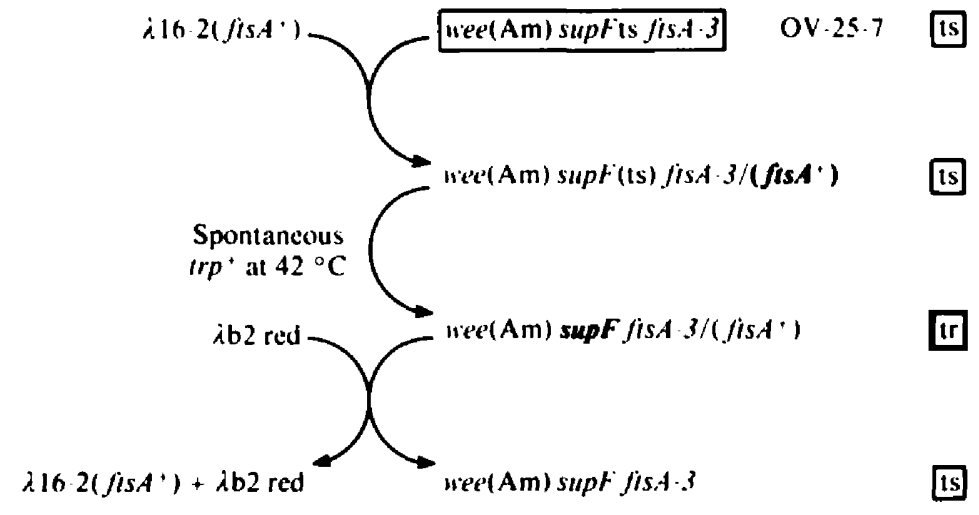

Fig. 2. Procedure used to test the presence of both $f(s / A-3(t s)$ and wee(Am) mutations in strain OV-25-7. The steps of the procedure described in the text are summarized as indicated in the legend to Fig. 1 . No strain designation has been given to these strains except to the problem strain, OV-25-7.

ability to grow at $42^{\circ} \mathrm{C}$ in the absence of tryptophan, occurred at a frequency $\left(10^{-7}\right)$ that could only be explained by a single mutational event (i.e. back mutation of supF). This indicated that an amber suppressible mutation in an essential function was present in the lysogen derived from OV-25-7. Displacement of the prophage from one temperature resistant, $\operatorname{trp}(\mathrm{Am}) \sup F$ fts $A-3$ (ts) $\left(\lambda 16-2\left[f_{t s} A^{+}\right]\right)$derivative of OV-25-7 was done by infection with $\lambda b 2$ red, as above, and produced non-lysogenic clones at the expected 3-4\% frequency (Herskowitz \& Hagen, 1980). These non-lysogenic clones were now all temperature sensitive. This last result proved that the original $\lambda 16-2\left[\mathrm{fts} \mathrm{A}^{+}\right]$phage particle that infected $\mathrm{OV}-25-7$ indeed carried a wild-type $\mathrm{fts} A$ gene able to complement a mutation in an essential gene present in that strain. In summary, from this set of results together with the pedigree of OV-25-7, we concluded that the relevant genotype of OV-25-7 was: ftsA-3(ts) wee(Am) sup $F(\mathrm{ts})$.

The morphology of OV-25-7 at $30^{\circ} \mathrm{C}$ was that expected from its $0 \mathrm{~V}-25$ background (Martínez-Salas \& Vicente, 1980) (Fig. 3). At $42^{\circ} \mathrm{C}$ it showed the inhibition of cell division characteristic of the ftsA mutation (dislocated filaments) (Tormo et al., 1980). This morphology confirmed our conclusions on its genotype. 


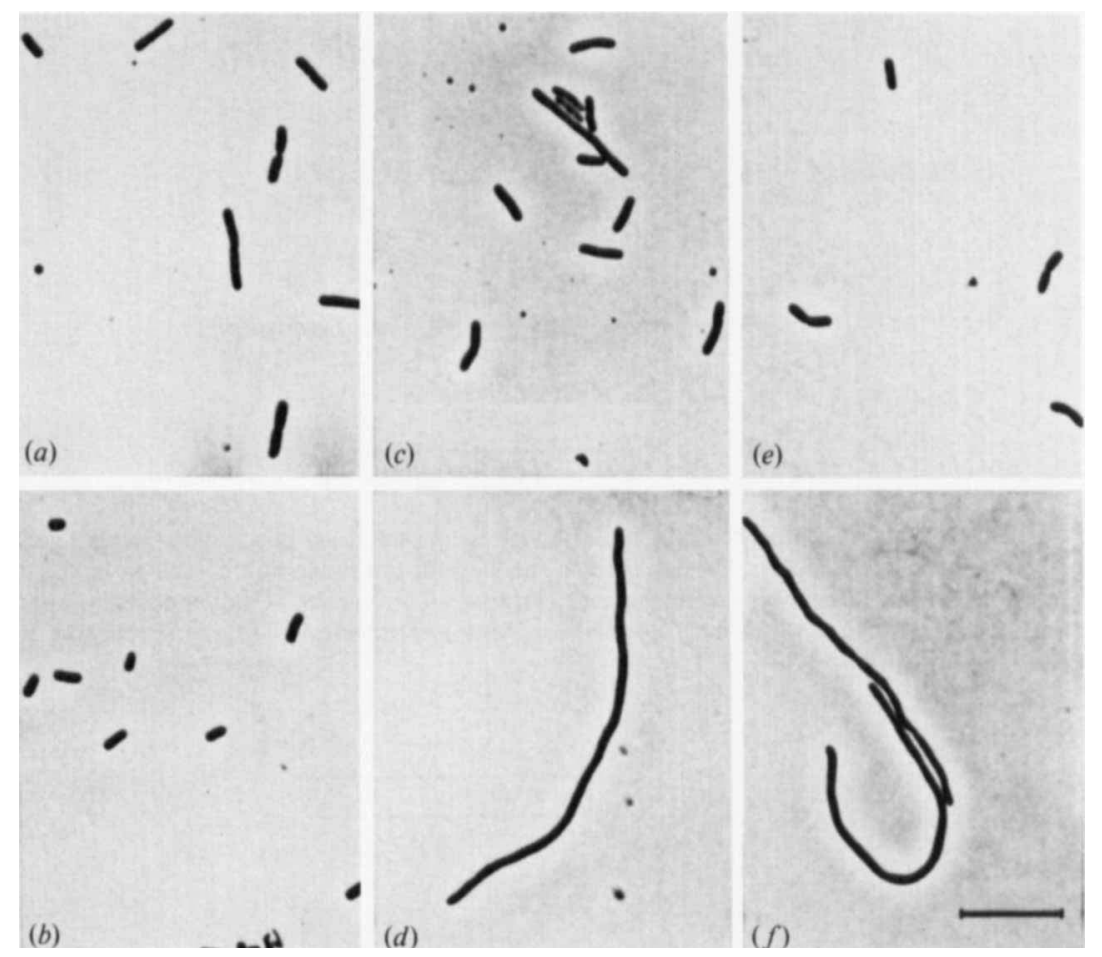

Fig. 3. Morphology of the double mutant OV-25-7 (fisA-3ts wee(Am) supFis) compared to the morphology of the single mutants OV-25 (wee(Am) supF(ts)) and D-3 (ftsA-3(ts)) at $30^{\circ} \mathrm{C}$ and after a 180 min incubation at $42^{\circ} \mathrm{C}$. OV-25: $30^{\circ} \mathrm{C}(a), 42^{\circ} \mathrm{C}(b) ; 0 V-25-7: 30^{\circ} \mathrm{C}(c), 42^{\circ} \mathrm{C}(d) ; D-3: 30^{\circ} \mathrm{C}(e)$, $42^{\circ} \mathrm{C}(f)$. Bar marker, $10 \mu \mathrm{m}$.

\section{Kinetics of growth and cell length increase in the presence or absence of Wee after division inhibition}

Since one of the phenotypic characteristics of wee cells is the decrease in mean cell length after a shift to $42^{\circ} \mathrm{C}$ (Martinez-Salas \& Vicente, 1980) it was very important to find if the mean cell length of the double mutant, $f t s A-3$ wee, was comparable at $42^{\circ} \mathrm{C}$ to that of the $f t s A-3$ strain, or if it was shorter.

The kinetics of increase in mean cell length after division inhibition in the presence or absence of wee was very similar, the filaments of the double mutant wee fts $A-3$ being as long as the fisA-3 ones (Fig. $4 b$ ); moreover, the cell length distribution of both populations showed no significant relative differences when shifted to the restrictive temperature (Fig. 5). The mean length of OV-2 (wild-type) and OV-25 (wee) cells behaved as expected from their genotypes (Fig. $4 a$ ).

An estimate of the amount of mass per unit length was obtained by measuring protein concentration in cultures of the four strains, OV-2, OV-25, D-3 and OV-25-7, under both permissive and restrictive conditions. The results in Fig. $4(c, d)$ indicate that an increase in protein content per unit cell length is only found in strain OV-25 at $42^{\circ} \mathrm{C}$. It seems, then, that in the absence of Wee, mass per unit length increases if cell division is allowed, but not when it is blocked. These results would agree with the suggested role of Wee being in co-ordination of elongation and division.

Cell buoyant density in the presence or absence of wee after division inhibition

In order to detect even small changes in buoyant density, cultures were sedimented to equilibrium through Ludox/polyvinylpyrrolidone gradients (Martinez-Salas \& Vicente, 1980; 

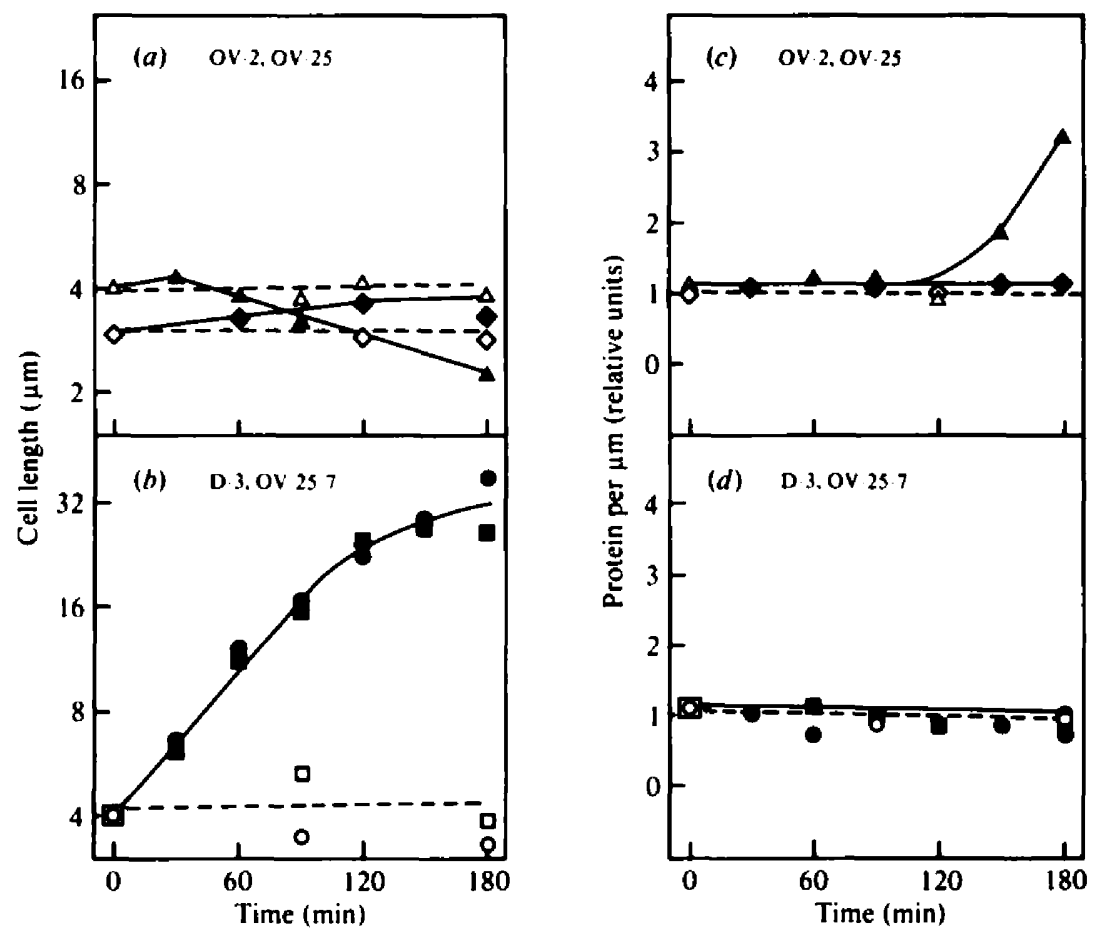

Fig. 4. Kinetics of mean cell length $(a, b)$ and protein per unit length $(c, d)$ increases in D-3 ( $f t s A-3(t s))$, OV-25-7 ( fisA-3(ts) wee(Am) supF(ts), OV-2 and OV-25 (wee(Am) supF(ts)). Cultures of the strains growing as described in the text were divided into two portions at time zero. One portion was kept at $30^{\circ} \mathrm{C}$ and the other one was shifted to $42^{\circ} \mathrm{C}$. Samples were withdrawn at the times indicated and mean cell length and total protein were measured as described in the text. Filled symbols and solid line, $42^{\circ} \mathrm{C}$; open symbols and broken line, $30^{\circ} \mathrm{C} . \diamond, \mathrm{OV}-2 ; \triangle \triangle, \mathrm{OV}-25 ; \mathrm{OO}, \mathrm{D}-3 ; \square \square$ OV-25-7. A minimum of 100 cells was measured to calculate mean cell length. Initial value for protein per unit length was $65 \mathrm{fg}_{\mathrm{gm}}^{-1}$, OV-2: $52 \mathrm{fg} \mu \mathrm{m}^{-1}$, OV-25; $66 \mathrm{fg} \mu \mathrm{m}^{-1}$, OV-25-7: $71 \mathrm{fg}_{\mathrm{gm}}^{-1}, \mathrm{D}-3$.

Martinez-Salas et al., 1981; Wolff, 1975). The mean buoyant density of OV-25-7 cells did not significantly deviate from the normal values, even under conditions in which both the Wee function and cell division were absent (Table 1).

When the buoyant density distribution of the wild-type, OV-25, D-3 and OV-25-7 at 30 and $42^{\circ} \mathrm{C}$ were compared (Fig. 6) we found that over $90 \%$ of the cells, in an OV-25-7 population that had been incubated at $42^{\circ} \mathrm{C}$ for $180 \mathrm{~min}$, banded at densities similar to or smaller than the wildtype OV-2 grown under the same conditions. OV-25-7 cells showed a distribution of cell densities at $42^{\circ} \mathrm{C}$ broader than the other strains but the percentage of the population that banded at low densities was relatively small (compare the results of Fig. 6 with the mean values of Table 1).

Part of the population of OV-25 (5\%) is filamentous and at $42{ }^{\circ} \mathrm{C}$ these cells band at densities similar to the wild-type (Martinez-Salas \& Vicente, 1980). In addition, microscopical examination revealed that around $20 \%$ of the OV-25-7 filaments formed at $42{ }^{\circ} \mathrm{C}$ underwent lysis after elution from the gradient. It was, therefore, very important to confirm not only that the mean buoyant density did not change, but also that individual cells did not become denser during the course of the experiment; otherwise the results shown in Table 1 could be criticized, as a potential increase in density could be counteracted by lysis. If the mean buoyant density of OV-25-7 at $42{ }^{\circ} \mathrm{C}$ were then a result of two opposite events (increase in density versus lysis), cells of high density should appear. Examination of the buoyant-density distribution of OV-25-7 at $42{ }^{\circ} \mathrm{C}$ compared to those of OV-25, OV-2 and D-3 revealed that there were very few cells present in the fractions of high density (less than $7.5 \%$ of the population, Fig. 7). Moreover, the 


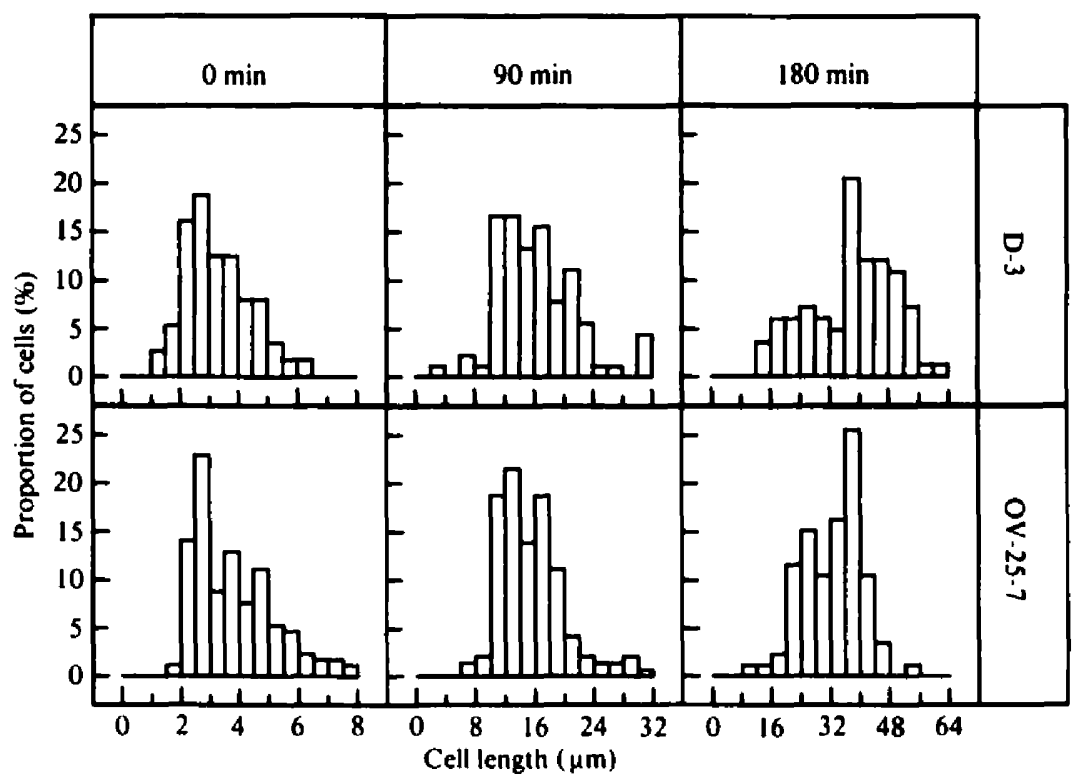

Fig. 5. Cell length distributions of strains D-3 and OV-25-7 at different times of incubation at $42^{\circ} \mathrm{C}$. Cultures of strains D-3 and OV-25-7 growing at $30^{\circ} \mathrm{C}$ were transferred to $42{ }^{\circ} \mathrm{C}$ at time zero. At the times indicated, samples were withdrawn, and the cells were photomicrographed and their lengths measured, as described in the text. A minimum of 100 cells was measured in each sample. Note the different scales for each time of withdrawal.

Table 1. Mean buoyant density in the presence or absence of the wee gene product when division is allowed or inhibited

\begin{tabular}{|c|c|c|c|}
\hline \multirow[b]{2}{*}{ Strain } & \multicolumn{2}{|c|}{ Mean density ( $\mathrm{g} \mathrm{ml}^{-1}$ ) } & \multirow[b]{2}{*}{$\Delta(\%)+$} \\
\hline & $30^{\circ} \mathrm{C}$ & $42^{\circ} \mathrm{C}^{*}$ & \\
\hline $\begin{array}{l}\left.\text { OV-2 (wee } f i s A^{+}\right) \\
\text {D-3 (wee fisA-3 (ts)) } \\
\left.\text { OV-25 (wee(AM) fisA } A^{+}\right) \\
\text {OV-25-7 (wee (AM) fis }-3(\mathrm{ts}))\end{array}$ & $\begin{array}{l}1 \cdot 114 \\
1 \cdot 112 \\
1.096 \\
1 \cdot 104\end{array}$ & $\begin{array}{l}1 \cdot 107 \\
1 \cdot 107 \\
1 \cdot 116 \\
1 \cdot 105\end{array}$ & $\begin{array}{l}-0.63 \\
-0.45 \\
+1.82 \\
+0.09\end{array}$ \\
\hline
\end{tabular}

\footnotetext{
- Cells growing exponentially at $30^{\circ} \mathrm{C}$ were shifted to $42{ }^{\circ} \mathrm{C}$ and kept at this temperature for $180 \mathrm{~min}$ before centrifugation.

+ Percentage increase in mean buoyant density at $42^{\circ} \mathrm{C}$ relative to its value at $30^{\circ} \mathrm{C}$.
}

percentage of the population banding at densities higher than the mode of $\mathrm{OV}-25$ cell density at $42^{\circ} \mathrm{C}\left(1.122 \mathrm{~g} \mathrm{ml}^{-1}\right)$ was almost the same for $\mathrm{OV}-2$ and $\mathrm{OV}-25-7$ at $30^{\circ} \mathrm{C}$, and after incubation at $42^{\circ} \mathrm{C}$ for either 120 or $180 \mathrm{~min}$ (Fig. 7). In contrast, when only the Wee function but not the FtsA one, was absent (strain OV-25) the proportion of the population banding at densities higher than 1.122 was now more than $50 \%$ under identical cultural and experimental conditions. On the other hand, division inhibition by itself had no effect on the distribution of buoyant density of strain D-3, which banded at both temperatures within density values similar to the wild-type strain.

\section{DISCUSSION}

As cell division in $E$. coli occurs at regular intervals and cell length increases continuously, the length at division for a given growth rate is almost constant. The construction of a double ftsA(ts) wee(Am) mutant strain allowed us to ask whether the constancy of length at division is a 


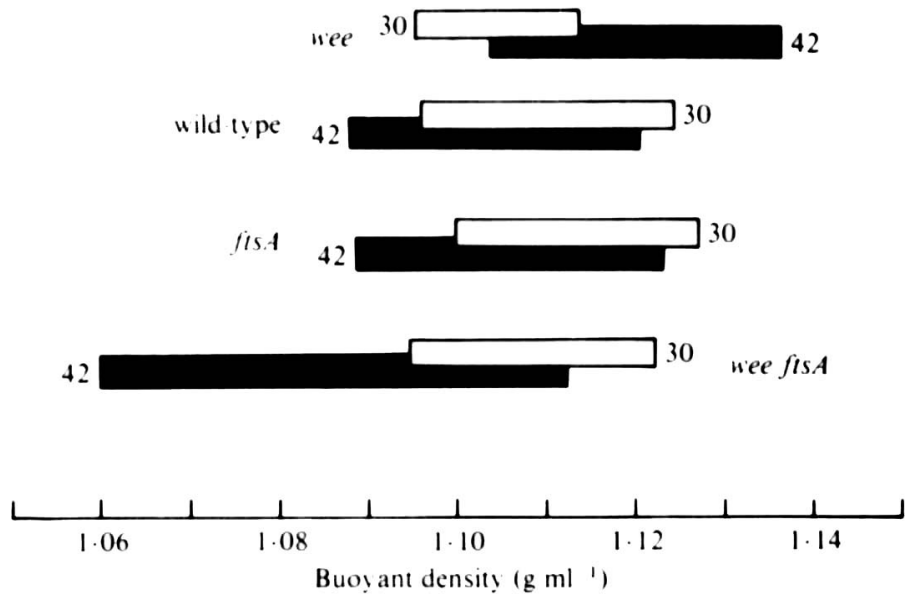

Fig. 6. Buoyant density distribution in the presence and absence of Wee. Buoyant density distributions of cultures growing exponentially at $30^{\circ} \mathrm{C}$ or shifted $1042^{\circ} \mathrm{C}$ for $180 \mathrm{~min}$ were obtained as described in the text. The results are plotted here as the density band comprising $90 \%$ of the cells in each population. Open bars $30^{\circ} \mathrm{C}$; filled bars $42^{\circ} \mathrm{C}$. The $f t s A$ strain was D-3; the wee strain was $\mathrm{OV}-25$; the wee fts $A$ strain was OV-25-7; and the wild-type strain was OV-2.

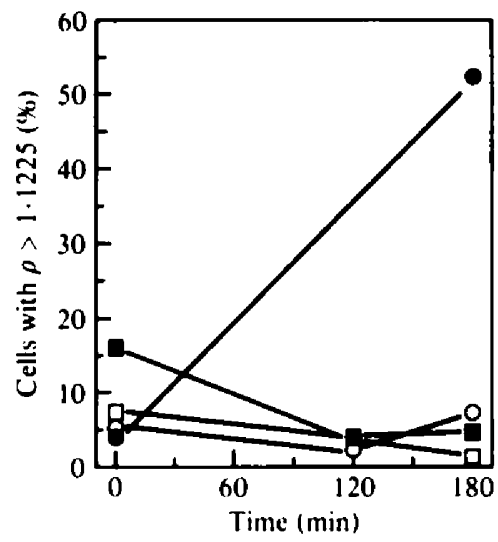

Fig. 7. Percentage of cells with buoyant density higher than that of the mode of distribution of OV-25 cells $\left(1 \cdot 1225 \mathrm{~g} \mathrm{ml}^{-1}\right)$. Cultures of the different strains growing at $30^{\circ} \mathrm{C}$, as described in the text, were shifted to $42^{\circ} \mathrm{C}$ at time zero and samples were withdrawn at the times indicated. Buoyant density distributions were obtained as described in the text. The strains used were: $D-3, f t s A-3(t s)(O) ; O V-25$,

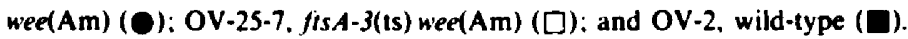

passive result of growth being solely controlled by periodic events, such as initiation of chromosome replication, that are not coupled to cell elongation (Donachie et al., 1976), or, on the other hand, if some co-ordination between the division and elongation pathways exists.

Construction of a strain harbouring two different conditional lethal lesions was facilitated by introducing one ts allele of one of the genes $(f t s A)$ and an amber suppressible allele of the other gene (wee) into a temperature sensitive amber suppressor background. This procedure can be used for any pair of genes provided that an amber allele of the second gene and a suitable lambda vector carrying the wild-type allele of the first gene are available.

The analysis of the physiological behaviour of the double mutant showed that, contrary to what is observed in the wee mutant, buoyant density at the restrictive temperature was no higher than in the wild-type. The inhibition of cell division alone, by the ftsA-3 mutation, had no effect on cell buoyant density. Although this last result provided a suitable control it was not totally 
expected, judging from the currently published data. Inhibition of cell division may, theoretically, cause variations in buoyant density due to two different effects. A small decrease in density would be expected as a consequence of filamentation, as it would prevent the formation of polar caps. The net gain of surface area in a filament, compared to division into two cells, is zero, as the surfaces of the sides of a cylinder and the spheres inscribed in it are equal; but the volume of the cylinder is bigger, and this small increase in volume could cause a decrease in buoyant density. On the other hand, an increase in density could be postulated as a filament elongates if the cell diameter decreases during elongation (Trueba $\&$ Woldringh, 1980). As no effect of the $f(s A$ mutation alone was found on buoyant density (Figs 6 and 7; Table 1), we concluded that it was safe to assume that our results with the double mutant were due only to the wee mutation, in the presence or absence of cell division. It may well happen that both theoretical effects on density cancel each other out in filaments.

The existence of a part of the population of filaments of strain OV-25-7 that lysed at $42{ }^{\circ} \mathrm{C}$ could cast doubts on our conclusions. However, the fact that the percentage of cells of density higher than $1.122 \mathrm{~g} \mathrm{ml}^{-1}$ (the mode of OV-25 cells at $42{ }^{\circ} \mathrm{C}$ ) was lower than $5 \%$ at several time intervals along the course of the temperature shock and remained at values similar to those found in wild-type populations (Fig. 7) suggested that our observations were not the consequence of two opposite effects, increases in buoyant density and lysis, cancelling each other out. We have found that some of the $5 \%$ of the filaments present in OV-25 populations undergo lysis at $42^{\circ} \mathrm{C}$, but why the introduction of an $\mathrm{fts} A$ mutation in a wee background favours cell lysis is unknown; we have also found that inhibition of cell division with furazlocillin, an antibiotic that specifically binds to penicillin binding protein 3, caused extensive cell lysis in OV -25 at $42^{\circ} \mathrm{C}$ (results not shown). That Wee may form part of the bacterial envelope remains as a suggestive but unproven possibility.

Our results, both of buoyant densities and of protein content per unit length, are not compatible with models in which Wee is involved in the physical event of elongation or in its regulation. These models cannot easily account for our finding that cell density and protein per unit length, in the absence of Wee, remained constant only when division was blocked. That is, if cell elongation and division were related in a passive way, and if Wee were then acting solely on elongation, we would have expected an increase in both parameters, independent of cell division, as a result of elongation taking place at a lower rate relative to mass increase (MartinezSalas \& Vicente, 1980). Our results (Figs 4,6 and 7; Table 1) show that this is not the case.

We propose then, that under normal circumstances, Wee plays a role in cell division by determining, for every growth rate, the length at which a cell divides; that is, Wee co-ordinates elongation and division. In the absence of the Wee protein the cell would divide at lengths quite close to twice the proposed minimum unit length of $E$. coli B/r A and K12 (OV-2) (Donachie $e t$ al., 1976; Martinez-Salas \& Vicente, 1980). It is tempting to speculate then that Wee might be a positional mechanism that avoids premature septation when the growth rate is faster than zero. A timing mechanism also would be compatible with our results. We could then ask about the behaviour of the wee(Am) mutant during the transition period. The question of what happens during the transition period, when the Wee protein stops being synthesized, is obviously related to whether Wee is a positional or a timing mechanism, and an answer should wait until missense alleles of wee are isolated and studied.

This work was supported by grant 3163-79 from Comisión Asesora de Investigación Cientifica y Técnica. E. M. -S and A. G. -C. were supported by fellowships from the Consejo Superior de Investigaciones Cientificas. A. T. was on leave from Colegio Universitario 'Arcos del Jalón' Universidad Complutense de Madrid.

\section{REFERENCES}

Arber, W., Enquist, L., Hohn, B., Murray, N. E. \& Murray, K. (1983). Experimental Methods for use with Lambda. In Lambda II, pp. 433-466. Edited by
R. W. Hendrix, J. W. Roberts, F. W. Stahl \& R. A. Weisberg. New York: Cold Spring Harbor Laboratory. 
Borck, K., Beggs, J. D., Brammar, W. J., Hopkins, A. S. Murray, N. E. (1976). The construction in vitro of transducing derivatives of phage lambda. Molecular and General Genetics 146, 199-207.

Cullum, J. \& Vicente, M. (1978). Cell growth and length distributions in Escherichia coli. Journal of Bacteriology 134, 330-337.

Donachie, W. D. (1968). Relationship between cell size and time of initiation of DNA replication. Nature, London 219, 1077-1079.

DONAchie, W. D., BegG. K. J. \& Vicente, M. (1976). Cell length, cell growth and cell division. Nature. London 264, 328-333.

Herskowitz, I. \& HaGen, D. (1980). The lysislysogeny decision of phage $\lambda$ : explicit programming and responsiveness. Annual Review of Genetics 14. 399-445.

Jones, N. C. \& Donachie, W. D. (1973). Chromosome replication, transcription and control of cell division in Escherichia coli. Nature New Biology 243, 100 103.
LutKenhaus, J. \& Donachie, W. D. (1979). Identification of the fisA gene product. Journal of Bacteriology. 137, 1088-1094.

Martínez-Salas, E. \& Vicente, M. (1980). Amber mutation affecting the length of Escherichia coli cells. Journal of Bacteriology 144, 532-541.

Martínez-Salas, E., Martin, J. A. \& Vicente, M. (1981). Relationship of Escherichia coli density to growth rate and cell age. Journal of Bacteriology 147. 97-100.

Tormo, A., Martínez-Salas, E. \& Vicente, $M$. (1980). Involvement of the ftsA gene product in late stages of the Escherichia coli cell cycle. Journal of Bacteriology 1, 806-813.

Trueba, F. J. \& Woldringh, C. L. (1980). Changes in cell diameter during the division cycle of Escherichia coli. Journal of Bacteriology' 142, 869-878.

WolFF, D. A. (1975). The separation of cells and subcellular particles by colloidal silica density gradient centrifugation. Methods in Cell Biology 10. 85-104. 